\title{
Memory of Natural Killer Cells: A New Chance against Mycobacterium tuberculosis?
}

\begin{abstract}
José Alberto Choreño Parra ${ }^{1,2}$, Nayeli Martínez Zúñiga ${ }^{3}$, Luis Antonio Jiménez Zamudio', Luis Armando Jiménez Álvarez², Citlaltepetl Salinas Lara ${ }^{4 *}$ and Joaquín Zúñiga ${ }^{2 *}$

'Laboratory of Clinical Immunology I, Escuela Nacional de Ciencias Biológicas, Instituto Politécnico Nacional, Mexico City, Mexico, ${ }^{2}$ Laboratory of Immunobiology and Genetics, Instituto Nacional de Enfermedades Respiratorias "Ismael Cosío Villegas, Mexico City, Mexico, ${ }^{3}$ Brain Bank, Department of National Laboratories of Experimental Services, Centro de Investigación y de Estudios Avanzados (CINVESTAV), Instituto Politécnico Nacional, Mexico City, Mexico, ${ }^{4}$ Department of Pathology, Instituto Nacional de Neurología y Neurocirugía "Manuel Velasco Suárez", Mexico City, Mexico
\end{abstract}

OPEN ACCESS

Edited by:

Andrea Sant

David H. Smith Center for Vaccine Biology and Immunology,

United States

Reviewed by:

Karl Kai McKinstry,

University of Central Florida,

United States

Shahram Salek-ardakani,

Pfizer (United States),

United States

*Correspondence:

Citlaltepet/ Salinas Lara

cisala69@hotmail.com;

Joaquín Zúñiga

joazu@yahoo.com

Specialty section:

This article was submitted

to Immunological Memory,

a section of the journal

Frontiers in Immunology

Received: 29 May 2017

Accepted: 28 July 2017

Published: 14 August 2017

Citation:

Choreño Parra JA,

Martínez Zúñiga $N$,

Jiménez Zamudio $L A$,

Jiménez Álvarez LA, Salinas Lara C

and Zúníga J (2017) Memory of

Natural Killer Cells: A New Chance against Mycobacterium tuberculosis?

Front. Immunol. 8:967.

doi: 10.3389/fimmu.2017.00967
Natural killer (NK) cells are lymphocytes of the innate immune system, which play an important role in the initial defense against a wide variety of pathogens, including viruses and intracellular bacteria. NK cells produce cytokines that enhance immune responses directed toward pathogens and also exert cytotoxic activity against infected cells, thereby eliminating the reservoir of infection. Their role in defense against Mycobacterium tuberculosis (Mtb) has been recently studied, and there is increasing evidence that highlight the importance of NK cell function during pulmonary tuberculosis (PTB), especially in the absence of optimal T-cell responses. Additionally, in the last years, it has been observed that NK cells mediate secondary responses against antigens to which they were previously exposed, an ability classically attributed to lymphocytes of the adaptive branch of immunity. This phenomenon, called "innate memory," could have important implications in the efforts to develop therapies and vaccines to improve the initial phases of immune reactions against different microorganisms, especially those to which there is not yet available vaccines to prevent infection, as is the case for tuberculosis. Therefore, the possibility of inducing memory-like NK cells ready to act prior to contact with Mtb or during the earliest stages of infection becomes quite interesting. However, our understanding of the mechanisms of innate memory remains incomplete. Here, we review recent literature about the mechanisms involved in the formation and maintenance of NK cell memory and the role of these cells in the immune response during tuberculosis. Finally, we discuss if the current evidence is sufficient to substantiate that NK cells exert more rapid and robust secondary responses after consecutive encounters with Mtb.

Keywords: natural killer cells, innate memory, memory-like natural killer cells, Mycobacterium tuberculosis, innate immunity

\section{INTRODUCTION}

Natural killer (NK) cells are innate lymphocytes with cytotoxic activity that cannot be classified within T- and B-cell lineages, as they differ from these lymphocytes in expression of CD56 (NCAM) and a lack of CD3 and CD19 (1). NK cells are part of group 1 of innate lymphoid cells (ILC1) (2) 
and were originally referred to as "natural killers" due to their intrinsic ability to induce lysis of target cells without previous antigen exposure $(3,4)$. Although NK cells use non-antigen specific mechanisms to exert effector functions, a growing body of evidence supports the idea that NK cells can exert recall responses against previously recognized antigens (5). This phenomenon, referred to as "innate memory," remained unnoticed for a long time as NK cells are constitutively "ready to act" and were not thought to improve their effector capacity after repeated antigenic exposure. In contrast to this belief, multiple studies have demonstrated that NK cells become more efficient during secondary responses to viruses, haptens, and intracellular bacteria (6-12). Nonetheless, the evidence of secondary responses mediated by NK cells against mycobacteria remains controversial.

Mycobacteria are pathogens that have co-evolved with and caused infection in mammals over thousands of years, resulting in the development of many strategies to evade protective innate and adaptive immune responses $(13,14)$. As NK cells play a role in host defense against Mycobacterium tuberculosis $(M t b)$ and there is increasing evidence of the importance of NK cell function during pulmonary tuberculosis (PTB), the possibility that NK cells may develop more efficient responses upon secondary exposure to $M t b$ becomes an interesting question that needs to be experimentally explored. If NK cells were found to be more effective upon secondary exposure to antigen, this aspect of NK cell biology could be manipulated for clinical application. For example, exposure of NK cells to antigens from different strains of $M t b$ would be helpful in improving vaccine efficacy and perhaps enhancing innate immune responses against $M t b$ in the clinical landscape of tuberculosis pathogenesis. However, the mechanisms responsible for induction, maintenance, and regulation of memory-like NK cells specific for $M t b$ must be extensively investigated using in vitro assays, experimental animal models, and eventually in human clinical studies. In this review, we focus on the evidence generated during the last decade about NK cell memory and critically discuss the experimental data which support the hypothesis that NK cells exert more rapid and robust secondary responses after consecutive encounters with $M t b$.

\section{BIOLOGY OF NK CELLS}

Natural killer cells represent 5-15\% of circulating lymphocytes in peripheral blood and their half-life, both in humans and mice, is about 2 weeks (15). They can be found in the spleen, liver, lung, thymus, uterus, lymph nodes, and they are also recruited to locally-inflamed peripheral tissues (16). Their "homing" under normal conditions depends on the expression of chemokine receptors which guide them to various sites $(17,18)$.

Natural killer cell function is determined by a balance between signals from both activating and inhibitory membrane receptors. These receptors are germline encoded and do not undergo somatic rearrangement like T-cell receptors. Hence, these cells have a limited repertoire, which allow them to recognize a reduced number of ligands, many of which are related to molecules of the major histocompatibility complex class I (MHC-I) $(19,20)$. Induction and maintenance of $\mathrm{NK}$ cell function is determined by NK cell receptors binding to their respective ligand, leading to subsequent activation of intracellular tyrosine-based activating motifs or intracellular tyrosine-based inhibitory motifs (ITIM), resulting in an activating or inhibitory effect, respectively $(21,22)$. Under homeostatic conditions, upon NK cell receptor binding of MHC-I expressed by normal (i.e., non-tumorigenic or uninfected) cells, SHP-1 and SHP-2 protein tyrosine phosphatases are recruited to ITIM present in the intracellular domain of inhibitory NK cell receptors. This results in the arrest of tyrosine kinase-based activation signals, and no further action is taken (20). These inhibitory NK cell receptors belong to four different families of membrane-bound receptors, which recognize MHC-I molecules: the killer-cell immunoglobulin-like receptors (KIR), the immunoglobulin-like transcripts (also known as leukocyte immunoglobulin-like receptors, or CD85), the C-type lectin-like receptors (CLR) of the Natural Killer Group 2 [NKG2 heterodimers (i.e., CD94/NKG2A)], and the killer-cell lectin-like receptor subfamily A (also known as Ly49) $(21,23)$.

Alternatively, when mature NK cells interact with target cells expressing an abnormal or diminished level of MHC-I (such as in the case of viral infection), SHP-1 and SHP-2 are not recruited and activation signals mediated through the NK cell activating receptors are not suppressed. This leads to a predominance of activating stimuli, triggering the cytotoxic effector function of NK cells and subsequent target cell death, which promotes clearance of the infected cells. NK cells express a large range of activating receptors, which can be classified into four groups based on function and ligand interaction. First, they express the low affinity activating Fc receptor, CD16a (also known as Fc $\gamma$ RIIIa), which recognizes the Fc region of immunoglobulin 1 (IgG1) and 3 (IgG3) and mediates antibody-dependent cellular cytotoxicity (ADCC). Second is the expression of natural cytotoxicity receptors (i.e., NKp30, NKp44, and NKp46), which belong to the immunoglobulin superfamily. The last groups of activating receptors are of the same families as some of the inhibitory receptors: the CLR-NKG2 family (i.e., NKG2D) and the KIR family. These two families of receptors induce cytokine production and cytotoxic activity after binding by MHC-I-associated molecules expressed on the surface of infected or damaged cells (i.e., ULBP, MIC-A, MIC-B, RAE1, H60, and MULT1) (23) and viral proteins that are MHC-I-like [i.e., m157 encoded by mouse cytomegalovirus (MCMV)] (24). Moreover, NK cells can directly recognize microorganisms through the interaction of Toll-like receptors (TLR) with pathogen-associated molecular patterns expressed by the pathogen $(25,26)$.

In addition to the wide variability of receptors that regulate NK cell activity, there are several subpopulations of NK cells with different degrees of maturation, and hence, with diverse functional profiles. In mice, the extent of expression of CD11b and CD27 discriminates between subsets of different maturity. $\mathrm{CD}_{11} \mathrm{~b}^{\text {low }} \mathrm{CD} 27^{+}$cells are present in bone marrow and lymph nodes and have a more immature phenotype, while $\mathrm{CD} 11 \mathrm{~b}^{+}$ CD27 ${ }^{\text {low }}$ NK cells localized in blood, spleen, liver, and lung have cytotoxic capacity, the ability to produce cytokines in response to stimulation, and decreased replicative potential (27). In humans, NK cells are distinguished by the expression of CD16 and varying levels of expression of CD56, which can be used to discriminate different subpopulations of NK cells. Those cells expressing low 
levels of $\mathrm{CD} 56$, or $\mathrm{CD} 56^{\mathrm{dim}} \mathrm{CD} 16^{+}$, are mature, differentiated cells in the periphery with high cytotoxic activity. The $\mathrm{CD} 56^{\text {bright }} \mathrm{CD} 16^{-}$ NK cells are associated with a lower level of development and poor lytic function and produce cytokines when stimulated with IL-12, IL-15, and IL-18 (28). These subpopulations are frequently located within lymph nodes, sites which have been considered centers of production and maturation of NK cells (such as the thymus is for T cells), and required for the development of NK cell "self-tolerance" (29-33).

Although much of the role of NK cells in tumor surveillance and in the defense to infectious agents is related with their cytotoxic properties, cytokine production is also a prominent function that places these cells as key orchestrators and regulators of innate and adaptive immunities. Along with IFN- $\gamma$ and TNF- $\alpha$, the main NK cells-derived cytokines that exert proinflammatory effects on other hematopoietic and non-hematopoietic cells in response to infection $(34,35)$, there is a growing list of soluble mediators that can also be released after activation of NK cells in different settings, including regulatory IL-5, IL-10, IL-13 (36-38), pro-inflammatory IL-17 (39), epithelial regenerative and protective IL-22 $(40,41)$, the growth factor GM-CSF (42), as well as chemokines MIP- $1 \alpha$, MIP- $1 \beta$, IL- 8 , and RANTES (43-46). Such ability is triggered principally in response to other exogenous cytokines that supports the proliferation and function of NK cells (47), but as occurs with the cytotoxic activity, recognition of membrane-bound ligands on target cells also regulates the production of different mediators by certain NK cell subsets in humans (48). Moreover, NK cells can produce IL-2 to promote their proper activation after clustering in multicellular groups and come into cell-to-cell homotypic interactions (49).

\section{ROLE OF NK CELLS IN THE IMMUNE RESPONSE AGAINST M. tuberculosis}

Natural killer cells play an important role in the immune response against viruses and intracellular bacteria due to their ability to kill infected cells and to eliminate intracellular pathogen reservoirs (50). There are several examples in which NK cell activity is crucial for disease control; possibly, one of the most well-documented examples is the role of NK cells during cytomegalovirus (CMV) infection $(34,50-54)$. However, the participation of NK cells in the immune response during РТB has been underappreciated, despite the fact that NK cells are an important source of IFN- $\gamma$, a cytokine vital to the immune response against $M t b$ through activation of macrophages, and subsequent enhancement of bactericidal activity (55). Furthermore, NK cells produce IL-22, a cytokine that has been shown to have a protective role during chronic stages of infection by emergent hyper-virulent strains of $M t b(56,57)$.

In spite of the historic lack of attention received by NK cells during $M t b$-associated immunity, mounting evidence suggests that NK cell function is important during PTB. First, several studies in humans have revealed that the risk of developing the active form of disease is related with the phenotype and functional state of NK cells isolated from peripheral blood. In fact, there is a higher prevalence of the KIR group A haplotype (expressing more inhibitory KIR) among patients with active tuberculosis when compared with resistant individuals. Indeed, certain KIR genes have increased correlation with the likelihood to become ill (i.e., KIR3DL1, KIR2DL3, KIR2DS1, and KIR2DS5), whereas others associate with a protective phenotype (i.e., KIR3DS1, KIR2DS2) (58-61). Portevin et al. confirmed these observations by demonstrating NK cells from healthy individuals' respond to direct contact with $M t b$ and $M$. bovis BCG and that the degree of such responses was dependent on the KIR haplotype. Also, they observed that NK cells are recruited into the lung lesions of patients with chronic $M t b$ infection (62).

When cultured in the presence of live $M t b$ bacilli, both subpopulations of human NK cells (CD56 $6^{\text {bright }}$ and CD56 ${ }^{\mathrm{dim}}$ ) respond and exert effector functions (63). However, in patients with active PTB, there is reduced frequency of CD56 $6^{\text {bright }}$ cells in the peripheral leukocyte population, accompanied by decreased expression of NK cell activating receptors (NKp30, NKp46), resulting in declined functional capacity $(64,65)$. This functional impairment of NK cells is also associated with an increase in $\mathrm{CD} 4^{+}$ $\mathrm{CD}^{2} 5^{+}$regulatory $\mathrm{T}$ cells $\left(\mathrm{T}_{\mathrm{reg}}\right)$, which may regulate the activity of NK cells (66). It is unknown if such alterations in NK cell functionality are related to the risk of bacterial dissemination to extrapulmonary sites.

Although the evidence mentioned earlier supports a role for NK cells in the defense against $M t b$ in patients with chronic infection, it is important to remember that these cells are innate in nature and act early during microbial defense (50). Functional assessment of human NK cells during initial stages of PTB is difficult, as most patients with pulmonary disease are diagnosed long after initial contact with the bacillus. Therefore, studies in different animal models have been conducted to evaluate NK cell activity in the early phases of the immune response against tuberculosis, with contradictory results. Specifically, Feng et al. showed that during Mtb infection of Rag1- deficient mice (which lack $\mathrm{T}$ and $\mathrm{B}$ cells), NK cells drive the immune response and resistance against PTB by secreting IFN- $\gamma$ (67). In contrast, when $M t b$ infection occurs in T- and B-cell sufficient animals, NK cell depletion does not influence $M t b$ bacterial burden in the lungs or disease severity (68). This is in agreement with the evidence, both in mice and humans, of the redundancy of ILC activity in the context of a complete adaptive immune system $(69,70)$. Despite the perhaps redundant role NK cells play during tuberculosis in immunocompetent individuals, their role in protection against $M t b$ could be of particular relevance in cases of T-cell dysfunction, i.e., in individuals infected with human immunodeficiency virus (HIV). This concept is of great importance, as HIV/AIDS is the leading comorbidity in $M t b$-infected individuals, and according to the 2015 WHO Tuberculosis report, 35\% of HIV-related deaths were due to PTB (71).

Recent data suggest that NK cells may modulate the development of mycobacteria-specific adaptive immune responses. In this regard, Vankayalapati et al. demonstrated that NK cells isolated from human peripheral blood can regulate effector functions of $\mathrm{CD}^{+} \mathrm{T}$ cells in response to $M t b$ infection. NK cell depletion reduced the frequency of $\mathrm{CD} 8^{+} \mathrm{IFN}-\gamma^{+} \mathrm{T}$ cells and decreased their capacity to lyse infected macrophages after in vitro exposure to $M t b$ bacilli (72). In addition, NK cells induced lysis of expanded 
$\mathrm{CD} 4{ }^{+} \mathrm{CD} 25^{+} \mathrm{T}_{\text {reg }}$ after incubation with $M t b$-infected monocytes; this lysis was shown to be dependent on NK cell NKG2D recognition of ULBP-1 on the $\mathrm{T}_{\text {reg }}$ surface (73).

In vitro assays have also revealed specific interactions between NK cells with infected phagocytes as well as with bacilli in their extracellular form. Specifically, it was shown that NK cells efficiently recognize certain $M t b$ and $M$. bovis BCG cell wall components through TLR-2 and NKp44 receptors (26, $74,75)$. Of note, NKG2D and NKp46 activating receptors are ligated by ULBP-1 and vimentin, respectively, whose expression increases on the surface of macrophages that have ingested bacteria (76-78). After recognition of these ligands, NK cells release IFN- $\gamma$ and IL-22, increasing the bactericidal capacity of infected phagocytes and may perform cytotoxic measures against these infected cells to eliminate intracellular pathogen niches $(79,80)$. Moreover, activated NK cells kill extracellular mycobacterial bacilli by releasing perforin and granulysin, via a mechanism dependent on intracellular signaling pathways mediated by kinases such as ERK, JNK, and p38MAPK (81). Production of proinflammatory cytokines, specifically IFN- $\gamma$, also may be triggered by direct contact with $M t b$ antigen; this activity is enhanced by cell-to-cell interaction with dendritic cells and associated IL-12 signaling (82).

Finally, NK cells play a role during the development of protective immunity conferred by vaccination. Murine exposure to BCG was shown to increase the number of IL-22-producing NK cells, and $\mathrm{NK}$ cell depletion induced an expansion of $\mathrm{CD} 4^{+} \mathrm{CD} 25^{+} \mathrm{T}_{\text {reg }}$ during re-challenge with $M t b \mathrm{H} 37 \mathrm{Rv}$ as well as increased bacterial burden and diminished $\mathrm{T}$-cell responses (83).

\section{IMMUNOLOGICAL MEMORY MEDIATED BY NK CELLS}

Natural killer cells are classically categorized as members of the innate immune system, as it was thought that repeated encounter with antigen did not augment or enhance their effector functions. Notably, in 2006, Leary et al. demonstrated that NK cells had adaptive memory qualities by using a mouse model of hapteninduced contact hypersensitivity (CHS) (5). In the absence of both $\mathrm{T}$ and $\mathrm{B}$ cells, NK cells were sufficient to mediate CHS responses in a hapten-specific manner, as CHS only occurred in those instances where the hapten used during challenge was the same hapten used during sensitization. This study also supplied a more structured understanding of NK cell function and delineated the mechanisms NK cells use to circulate within lymphatic vessels and access lymph nodes, where antigen priming occurs. Once NK cells have been activated in secondary lymphoid organs, they migrate to the liver and reside there until antigen re-exposure, then home to sites of antigenic challenge. Moreover, transfer of liver-resident and not spleen-resident memory-like NK cells into healthy mice resulted in transfer of the hypersensitivity phenotype (5). Further analyses revealed later that liver NK cells with the ability to exert secondary responses to haptens belong to a specific subset (denoted by $\mathrm{CD} 49 \mathrm{a}^{+} \mathrm{DX} 5^{-}$) and that recall responses to subsequent contacts with haptens are dependent on the activity of NLRP3 inflammasome $(84,85)$.
Sun et al. subsequently found that MCMV infection elicited an immune response mediated by NK cells, which emulated all the hallmarks of a traditional memory response (7), characterized by an initial proliferation phase with clonal expansion of NK cells expressing the Ly49H receptor (which recognizes the m157 protein of the MCMV). This clonal expansion was dependent on Ly49H/DAMP12 signaling (receptor ligation, or "Signal 1") and IL-12 priming through STAT-4 activity (cytokine help or "Signal 2 "), as well as co-stimulation by DNAX accessory molecule 1 (co-stimulation or "Signal 3") (7, 86). After this proliferation phase, contraction of effector NK cells occurred by mitochondrial apoptosis and was followed by the development of a pool of memory cells, which survived cell death through mechanisms of mitophagy (87). Similar to T-cells (88), NK cells required IL-15 signaling as well as the regulatory activity of miR155 on Noxa and SOCS1 for optimal differentiation into memory-like NK cells $(89,90)$. This pool of memory-like NK cells resided in the spleen and other lymphoid and non-lymphoid organs. Interestingly, transfer of MCMV-memory-like NK cells into neonate mice resulted in protection from a lethal challenge of MCMV (7).

Similar to the findings in MCMV-infected mice, clonal expansion of CD94/NKG2C ${ }^{+} \mathrm{NK}$ cells was observed in humans seropositive for human cytomegalovirus (91-93) as well as in transplant recipients who either underwent $\mathrm{CMV}$ reactivation or were seronegative and had received organs from seropositive donors $(94,95)$. These data show that transfer of NK cells with long-lasting survival and enhanced antigen-specific activity is a viable immune mechanism in humans as well as mice. Clonal NK cell expansion in humans was also observed in response to other viral infections, such as hantavirus, chikungunya, hepatitis B virus, hepatitis C virus, and HIV (96-100). Further evidence of memory and clonal expansion of NK cells in response to viral infection was found using mouse models of immunization with antigens of genital HSV-2 virus (12), influenza virus, vesicular stomatitis virus, and even HIV, a pathogen that does not infect mice naturally. Moreover, this virus-specific immune response by NK cells and the associated protection are mediated only by those NK cells isolated from the liver expressing CXCR6 (6). Interestingly, influenza vaccination of healthy humans enhanced the amount of IFN- $\gamma$ produced by NK cells up to 6 months postimmunization (101). These data support that human NK cells, apart from expanding during antigen encounter, also display a better response in subsequent exposures to viral antigens, similar to that which occurs in mice. Although most of these recall responses occurred in the context of viral infection, it was recently documented that memory-like NK cells were expanded in response to infection with the intracellular bacterium Ehrlichia muris (9). This pathogen belongs to a genus of which it was recently reported that NK cells play an important role in the associated inflammatory responses (102). In addition, human and mouse NK cells display enhanced activity when they are primed with cytokines and later re-exposed to the same stimuli in conjunction with engagement of activating receptors by antibodies or cognate ligands (103-105).

Collectively, these studies support that immunological memory is an intrinsic property of NK cells conserved in vertebrates. Of note, NK cells have secondary responses against both previously 
unencountered antigens and antigens that have not represented an evolutionary pressure, as in the case of haptens and HIV infection, respectively, in murine models $(5,6)$. In addition, it has been observed that HIV elicits memory of long duration in macaques, a mammalian species that, as the mouse, is not the natural host of this virus (8). Nevertheless, there are several aspects of innate memory of NK cell subsets that remain poorly understood. One question is whether NK cells with the ability to mediate memory responses belong to a specific subgroup of conventional NK cells or if they are in fact lymphocytes of a different subset within the group 1 ILC? Second, what markers and patterns of expression can be used to identify these memory-like NK cells? To date, it is well established in mice that memory-like NK cells are located preferentially in the liver, but their specific phenotype has only been described in mouse models using haptens and MCMV (5, $7,84)$. It will be important to address if there is a specific NK cell subset induced by certain paired NK cell receptor-ligand interactions, or associated with different classes/types of pathogens and subsequent responses.

\section{EVIDENCE OF MEMORY AGAINST M. tuberculosis WITHIN NK CELL SUBSETS}

Different groups have recently sought to identify memory responses mediated by NK cells against mycobacteria, and the results have been contradictory, proving it difficult to define the importance of human NK cells in the immune pathogenesis of tuberculosis. NK cells isolated from pleural fluid of subjects with pleural effusion associated with active PTB express the memory marker CD45RO and produce higher amounts of IFN- $\gamma$ and IL-22 in response to stimulation with interleukins and $M$. bovis BCG when compared with CD45RO-cells $(106,107)$. As these NK cells were isolated from a specific inflamed anatomical site, it would be of great interest to assess whether peripheral and tissue resident NK cells also express CD45RO and if this expression confers enhanced effector functions against different species of mycobacteria.

Additional evidence in favor of memory against $M t b$ within NK cell subsets has been provided by Suliman et al., who found that BCG re-vaccination of subjects latently infected with $M t b$ induced long-term responses in NK cells, which persisted for up to 1 year after re-challenge (108). In this study, they also found that BCG vaccination of humans at birth induced augmented activity of NK cells in 5-week-old neonates. Another study also showed that BCG vaccination in healthy subjects promoted the production of proinflammatory cytokines, particularly IL- $1 \beta$, by NK cells in response to $M t b$ and other fungal pathogens 3 months after the initial exposure (109).

Meanwhile, Kawahara et al. were unable to demonstrate enhanced secondary responses by NK cells isolated from mice vaccinated with BCG (110). Using a mouse model of immunization with BCG, this group did not find functional differences between NK cells isolated from the spleens of vaccinated and unvaccinated animals, particularly in their capacity to produce cytokines after in vitro exposure to $M t b \mathrm{H} 37 \mathrm{Rv}$. Also, NK cells stimulated in vitro with BCG antigens did not have increased cytotoxicity against
$M t b$-infected macrophages (110). As Leary et al. had shown that the liver-resident NK cells were the subset responsible for enhanced responses $(5,111)$, it would have been beneficial to assess memory responses in NK cells isolated from tissues other than spleen, i.e., the liver, in these BCG vaccinated mice.

However, a recent study using an experimental model of $M t b$ infection in mice showed that BCG vaccination promoted an IL-21-dependent expansion of a CD3 ${ }^{-} \mathrm{NKp} 46^{+} \mathrm{CD} 27^{+}$ $\mathrm{KLRG}^{+}$memory-like NK cell subset residing in lymph nodes and spleen. These cells produced higher amounts of IFN- $\gamma$ compared to other subsets of NK cells and conferred protective responses against $M t b$ upon transfer to unvaccinated animals. This finding was also confirmed in vitro using latently infected human cells: $\mathrm{CD} 3^{-} \mathrm{CD} 56^{+} \mathrm{CD} 27^{+} \mathrm{NK}$ cells were able to reduce $M t b$ CFU when co-cultured with autologous infected macrophages more effectively than $\mathrm{CD}^{-} \mathrm{CD} 56^{+} \mathrm{CD} 27^{-} \mathrm{NK}$ cells. In addition, the responses of these $\mathrm{CD}^{-} \mathrm{NKp} 46^{+} \mathrm{CD} 27^{+} \mathrm{KLRG}^{+}$ cells were specific as in vitro exposure to Candida albicans did not induce NK cell expansion, as seen with $M t b$. This study is possibly the first evidence of the existence of a subpopulation of NK cells with the ability to mount recall responses against repeated exposures to $M t b$, highlighting the potential usefulness of memory-like NK cells to improve the efficacy of vaccination against $M t b$ (112).

\section{CHALLENGES}

It is important to mention that studies in humans that observed memory-like responses in NK cells isolated from pleural fluid in the context of tuberculous pneumonia are only descriptive and did not evaluate the parameters which characterize an effective adaptive immune response. This is the same situation for the work done by Kawahara et al. (110) whose data, although debatable, cannot be ignored. The fact that certain subsets of human NK cells respond more robustly after re-exposure to several strains of mycobacteria and to activation with non-antigenic stimuli does not necessarily mean that these are memory cells, even when such cells express markers classically attributed to adaptive lymphocytes with the ability to improve their function after subsequent contacts with pathogen-derived antigens. Although they might belong to the memory-like NK cell subset supposedly induced by cytokines, which mediate secondary responses to specific and non-specific re-challenges, the exact mechanisms that trigger their development and maintenance have not been vigorously evaluated. Additionally, we cannot rule out the possibility that these $\mathrm{CD}_{4} \mathrm{RO}^{+} \mathrm{NK}$ cells were expanded in response to other pathogens and became involved in the immune response to $M t b$ through a bystander mechanism.

At the same time, the lack of differences observed by Kawahara et al. in the splenic NK cell response to in vitro $M t b$ exposure between BCG vaccinated and unvaccinated animals does not mean that these cells do not "remember" previous antigen encounter and cannot exert secondary responses. Perhaps it is that these cells are simply not the subset capable of mounting a secondary response and it is only a matter of finding cells from an anatomical location, which harbor the effective subset, such as the liver. 
Therefore, an animal model is needed, which allows detailed evaluation of clonal NK cell proliferation in response to PTB, as that which occurs in case of MCMV infection (7). However, this will be difficult to achieve as there are no sufficient mouse models of tuberculosis that strictly emulate the natural infection, which occurs in humans, and there is a lack of an NK cell receptor that can easily identify or define clonal NK cells with antigen specificity. In addition, we still have no markers to delineate exactly which subpopulations of NK cells are able to develop memory-like qualities in mice. In this regard, it will be important to identify mouse NK cell subsets currently known to expand in response to $M t b$ infection, as well as those populations which possess surface molecules implicated in previous studies with other pathogens. Also, pathogen species-difference specificity will need to be assessed to understand the breadth of memory NK cells induced upon antigenic stimulation. Moreover, this model must address whether memory-like NK cells migrate to a specific anatomic site and evaluate whether these presensitized
NK cells confer protection when transferred to animals that have not previously come into contact with the pathogen. This last point is likely the most important aspect that future research should evaluate. Although the pleural effusion human studies support the existence of NK cell memory, they also call into question whether memory responses mediated by NK cells play a protective or pathogenic role, as the patients in this study developed severe disease complications. Moreover, although Suliman et al. observed that vaccination of neonates with BCG at birth induced enhanced responses in NK cells 5 weeks later (108), long-term follow-up is needed to find out if these responses persist indefinitely and whether they influence the risk of active PTB in the future, independently of the induction and activity of memory T cells.

In this regard, the study performed by Vankayalapati and colleagues utilizes almost all of the features that we propose an experimental model must possess to characterize immune memory mediated by NK cells in the context of $M t b$ infection.

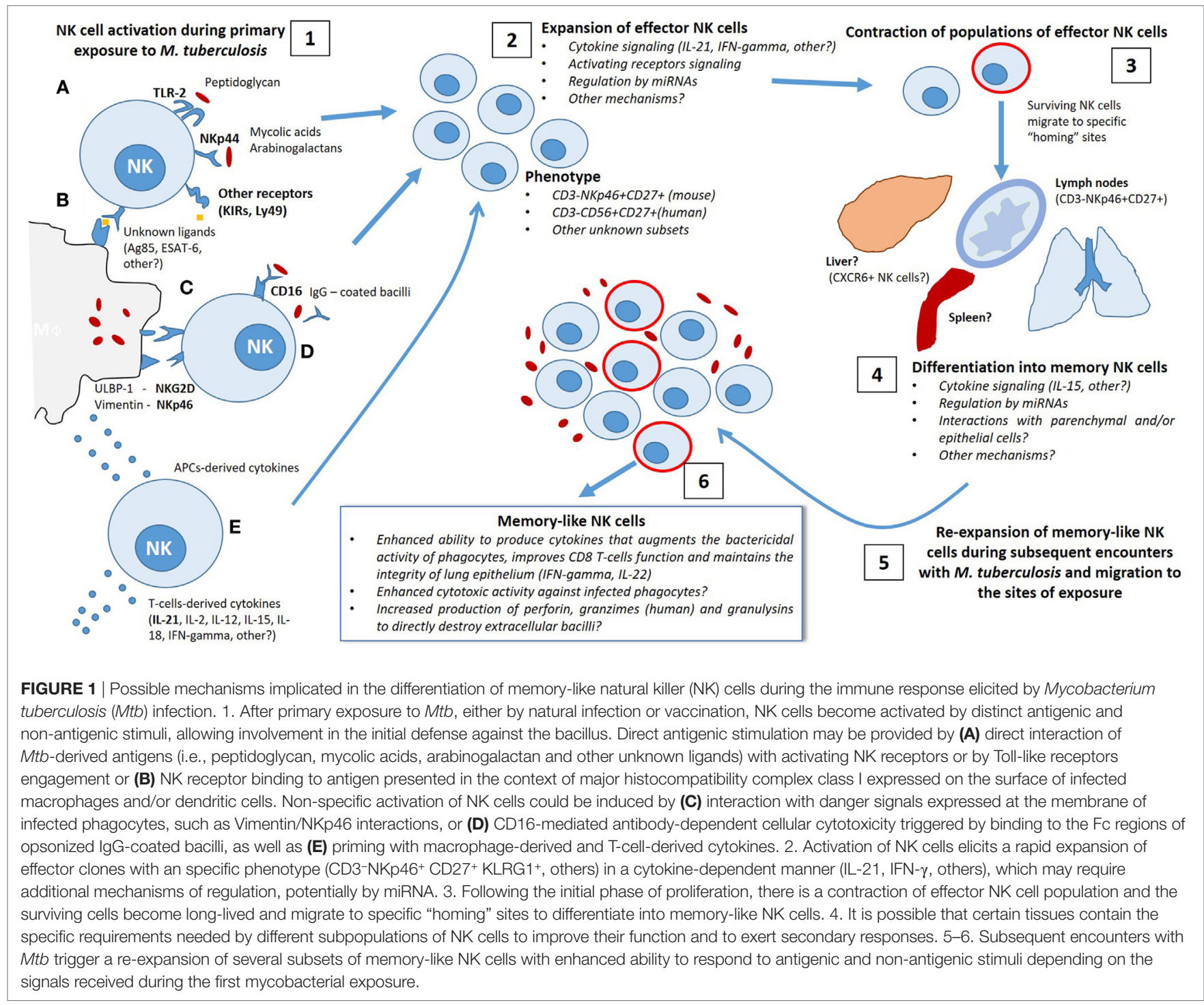


However, it would be of great interest to address if there is expansion of additional subsets of memory-like NK cells in tissues other than spleen and lymph nodes (i.e., the liver) and if such cells confer protection against $M t b$ infection. Also, other mechanisms regulating the proliferation and differentiation of memory-like NK cells must be evaluated, including a broader spectrum of cytokines that might be involved in the expansion of $\mathrm{CD}^{-} \mathrm{NKp} 46^{+} \mathrm{CD} 27^{+} \mathrm{KLRG} 1^{+} \mathrm{NK}$ cells as well as other subpopulations with distinct phenotypes. Moreover, further analysis is needed to reveal the receptors and $M t b$-derived antigens implicated in the activation and expansion of memory-like NK cells. Use of blocking antibodies and/or knockout animals lacking different NK cell membrane receptors would allow further study of these mechanisms. Finally, to determine whether expanded NK cell subsets protect from disease in humans, a comparative study is required that includes, in addition to subjects latently infected with $M t b$, both individuals with active PTB and those with disseminated disease.

In Figure 1, we show the possible signals involved in induction of NK cell secondary responses by several specific and nonspecific stimuli. We also highlight the mechanisms implicated in the differentiation of a subset of memory NK cells capable of responding more efficiently during repeated contact with $M t b$.

\section{ARGUMENTS IN FAVOR OF THE EXISTENCE OF NK CELL MEMORY AGAINST M. tuberculosis}

The fact that NK cell responses against haptens, viruses, and intracellular bacteria are characterized by hallmarks of adaptive immunological memory supports the hypothesis that NK cells can become sensitized and memory like in response to repeated exposure to $M t b$. Despite current controversial evidence supporting the existence of memory-like NK cells and their role in the immune pathogenesis of tuberculosis and that these findings must be confirmed in experimental animal models and in humans, we consider there are at least two reasonable arguments to support this assertion. First, some of the studies that defined memorylike qualities of NK cells were performed using animal models with infection by pathogens to which it is still unclear whether NK cells play an important role in the defense against them $(6,8)$. Second, this memory-like quality of NK cells was identified using a model of delayed hypersensitivity induced by haptens (5) and there is little evidence to support why NK cells would have need to "remember" a hapten encounter. Thus, it would appear that memory is an intrinsic characteristic of NK cells, independent of the target antigen.

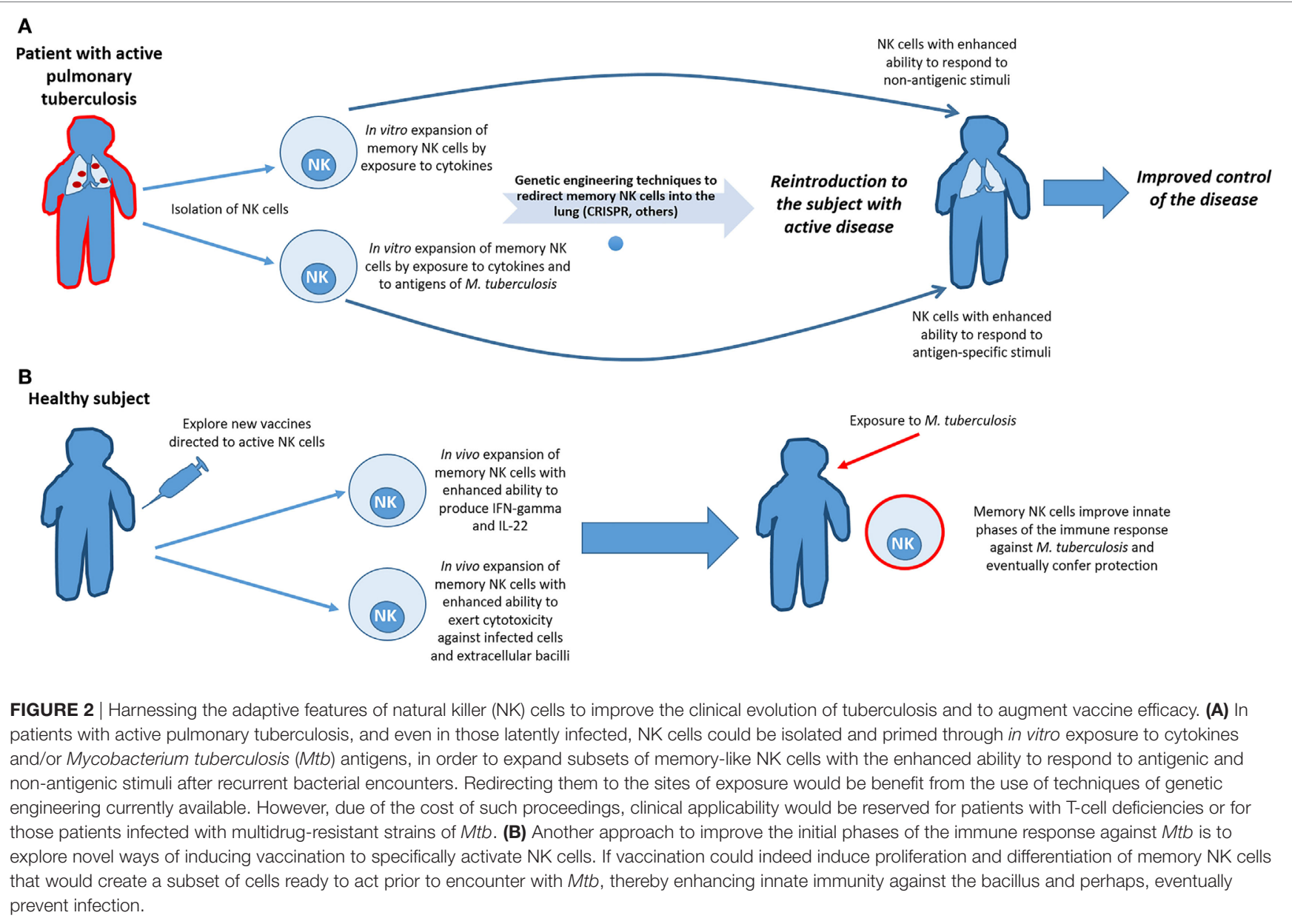


Although they do not possess antigen receptors generated by genetic rearrangement, NK cells do have receptors which allow direct antigenic contact, resulting in subsequent cellular activation $(74,75)$. Of note, while direct contact with target antigen is an important step in the generation of memory T cells, this step is not necessary for the development of memory-like NK cells. NK cells also undergo secondary responses following activation by cytokines $(103,104)$. In the context of proinflammatory environments found at the sites of infection, this cytokine stimulation may augment $\mathrm{NK}$ cell function, as is seen when $\mathrm{CD} 8^{+} \mathrm{T}$ cells differentiate into antigen-non-specific memory cells after being activated with cytokines through a "bystander" mechanism (113).

Finally, species of the mycobacterium complex have infected hominids for the past 3 million years and have supplied a constant evolutionary pressure for innate and adaptive cells of the mammalian immune system $(13,14)$. There is evidence of immunological memory existing prior to the emergence of lymphocytes $(114,115)$, and NK cells, as well as their progenitors, are more ancient with respect to the cells of the adaptive immune system (116). Therefore, during mammalian evolution, there has been ample time for NK cells to learn from contact with these ancient pathogens and modify responses against them, but, at the same time, $M t b$ may have acquired evolutionary advantages to evade such responses (117).

\section{CONCLUSION AND PERSPECTIVES}

The adaptive-like qualities of NK cells make them new targets for the development of cellular-mediated therapies to enhance innate phases of the immune response against different pathogens and improve the protection conferred by currently available vaccines. Specifically, in the case of $M t b$ infection, one approach to achieve this purpose would be to prime NK cells with cytokines that augment function and allow improved responses against new antigen-dependent or -independent signals within the lung lesions of tuberculosis patients. An alternative approach would be to sensitize and expand NK cells using in vitro bacterial exposure, followed by autologous transfer of the sensitized cells back into to the infected individual. Although these cells would not act in the innate phase of infection, as patients are already infected, the NK cells may have enhanced function that would be of special importance in individuals with impaired T-cell responses. Finally, the fact that NK cells are a source of IL-22 during PTB provides rational support for the use of NK cells as a target of new vaccines to improve IL-22 production. This approach could provide patients with a cytokine involved in maintaining lung epithelium integrity from the early stages of the disease and help to limit bacterial dissemination (see Figure 2).

For years, efforts to understand why the human immune system cannot eradicate $M t b$ have focused on T-cell biology.

\section{REFERENCES}

1. Trinchieri G. Biology of natural killer cells. Adv Imunol (1989) 47:187-376. doi:10.1016/S0065-2776(08)60664-1

2. Spits H, Bernink JH, Lanier LL. NK cells and type 1 innate lymphoid cells: partners in host defence. Nat Immunol (2016) 17(7):758-64. doi:10.1038/ni.3482
However, the emerging role of NK cells during immunopathology of tuberculosis, and the antigen-specific recall responses of these cells, appeals for a redirection of attention to this lineage of lymphocytes which may represent "a new chance" against $M t b$. Nevertheless, it is clear that much work remains to elucidate the molecular mechanisms, which regulate memorylike NK cell development and maintenance in response to $\mathrm{Mtb}$ infection. Also, immunologist has the task of ruling out possible collateral damage before implementing NK cells in protective strategies against $M t b$ and other pathogens since there are certain instances in which it has been possible to observe an association between the activity of NK cells with worsened outcomes and increased immunopathology (118120). Nonetheless, current evidence does not support this scenario in the context of tuberculosis, as the data suggest that dysfunction of these cells is related with increased likelihood to become ill; in addition, there are discrepancies in the results of animal models and human studies of other infectious and non-infectious disorders that remain unclarified (121-123). Once such gaps in the knowledge have been overcome, the inherent memory-like qualities of this innate subset of cells may in fact be an old and well-known weapon, which could be used to further enhance innate phases of immunity against tuberculosis, improve vaccine design and efficacy, and perhaps, even to help to prevent infection.

\section{AUTHOR CONTRIBUTIONS}

All authors listed have made a substantial, direct, and intellectual contribution to the manuscript and approved it for publication.

\section{ACKNOWLEDGMENTS}

The authors would like to thank Shabaana A. Khader Ph.D. and Kimberly Thomas Ph.D. at the Department of Molecular Microbiology, Washington University School of Medicine in St. Louis, MO, USA, for their critical reading, corrections, and comments on the manuscript.

\section{FUNDING}

JP is supported by the fellowship 597113 of the National Council of Science and Technology of México (CONACYT) to achieve his M.Sc. degree at Escuela Nacional de Ciencias Biológicas, IPN. NZ is supported by fellowship 600835 of the National Council of Science and Technology of Mexico (CONACYT). JZ is supported by grant 271197 of the National Council of Science and Technology of Mexico (CONACYT) and grant 2R01HL10542706A1 of the National Heart, Lung and Blood Institute, National Institutes of Health (NIH), USA. 
Characteristics of the killer cell. Eur J Immunol (1975) 5(2):117-1121. doi:10.1002/eji.1830050209

5. Leary JGO, Goodarzi M, Drayton DL, Von Andrian UH. T cell- and B cellindependent adaptive immunity mediated by natural killer cells. Nat Immunol (2006) 7(5):507-16. doi:10.1038/ni1332

6. Paust S, Gill HS, Wang B, Flynn MP, Ashley E, Senman B, et al. Critical role for CXCR6 in NK cell-mediated antigen-specific memory to haptens and viruses. Nat Immunol (2011) 11(12):1127-35. doi:10.1038/ni.1953

7. Sun JC, Beilke JN, Lanier LL, Francisco S. Adaptive immune features of natural killer cells. Nature (2009) 457(7229):557-61. doi:10.1038/nature07833

8. Reeves RK, Li H, Jost S, Blass E, Li H, Jamie L, et al. Antigen-specific NK cell memory in rhesus macaques. Nat Immunol (2016) 16(9):927-32. doi:10.1038/ ni.3227

9. Habib S, El Andaloussi A, Hisham A, Ismail N. NK cell-mediated regulation of protective memory responses against intracellular ehrlichial pathogens. PLoS One (2016) 11(4):e0153223. doi:10.1371/journal.pone.0153223

10. O'Sullivan TE, Sun JC. Generation of NK cell memory during viral infection. J Innate Immun (2015) 7(6):557-62. doi:10.1159/000375494

11. Gillard GO, Bivas-Benita M, Hovav AH, Grandpre LE, Panas MW, Seaman MS, et al. Thy $1^{+}$NK cells from vaccinia virus-primed mice confer protection against vaccinia virus challenge in the absence of adaptive lymphocytes. PLoS Pathog (2011) 7(8):e1002141. doi:10.1371/journal. ppat.1002141

12. Abdul-Careem MF, Lee AJ, Pek EA, Gill N, Gillgrass AE, Chew MV, et al. Genital HSV-2 infection induces short-term NK cell memory. PLoS One (2012) 7(3):e32821. doi:10.1371/journal.pone.0032821

13. Gagneux $S$. Host-pathogen coevolution in human tuberculosis. Philos Trans $R$ Soc Lond B Biol Sci (2012) 367(1590):850-9. doi:10.1098/rstb.2011.0316

14. Brites D, Gagneux S. Co-evolution of Mycobacterium tuberculosis and Homo sapiens. Immunol Rev (2015) 264(1):6-24. doi:10.1111/imr.12264

15. Zhang Y, Wallace DL, De Lara CM, Ghattas H, Asquith B, Worth A, et al. In vivo kinetics of human natural killer cells: the effects of ageing and acute and chronic viral infection. Immunology (2007) 121(2):258-65. doi:10.1111/j.1365-2567.2007.02573.x

16. Parolini S, Santoro A, Marcenaro E, Luini W, Massardi L, Facchetti F, et al. The role of chemerin in the colocalization of NK and dendritic cell subsets into inflamed tissues. Blood (2007) 109(9):3625-32. doi:10.1182/ blood-2006-08-038844

17. Walzer T, Chiossone L, Chaix J, Calver A, Carozzo C, Garrigue-Antar L, et al. Natural killer cell trafficking in vivo requires a dedicated sphingosine 1phosphate receptor. Nat Immunol (2007) 8(12):1337-44. doi:10.1038/ni1523

18. Kim CH, Pelus LM, Appelbaum E, Johanson K, Anzai N, Broxmeyer HE. CCR7 ligands, SLC/6Ckine/Exodus2/TCA4 and CKbeta-11/MIP-3beta/ELC, are chemoattractants for $\mathrm{CD} 56^{+} \mathrm{CD} 16^{-} \mathrm{NK}$ cells and late stage lymphoid progenitors. Cell Immunol (1999) 193(2):226-35. doi:10.1006/cimm.1999.1483

19. Lanier LL. NK cell recognition. Annu Rev Immunol (2005) 23:225-74. doi:10.1146/annurev.immunol.23.021704.115526

20. Lanier LL. Up on the tightrope: natural killer cell activation and inhibition. Nat Immunol (2008) 9(5):495-502. doi:10.1038/ni1581

21. Vivier E, Nunès JA, Vély F. Natural killer cell signaling pathways. Science (2004) 306(5701):1517-9. doi:10.1126/science.1103478

22. Kruse PH, Matta J, Ugolini S, Vivier E. Natural cytotoxicity receptors and their ligands. Immunol Cell Biol (2014) 92(3):221-9. doi:10.1038/icb.2013.98

23. Long EO, Kim HS, Liu D, Peterson ME, Rajagopalan S. Controlling natural killer cell responses: integration of signals for activation and inhibition. Annu Rev Immunol (2013) 31:227-58. doi:10.1146/annurev-immunol-020711075005

24. Arase H, Mocarski ES, Campbell AE, Hill AB, Lanier LL. Direct recognition of cytomegalovirus by activating and inhibitory NK cell receptors. Science (2002) 296(5571):1323-6. doi:10.1126/science.1070884

25. Sivori S, Falco M, Della Chiesa M, Carlomagno S, Vitale M, Moretta L, et al. CpG and double-stranded RNA trigger human NK cells by toll-like receptors: induction of cytokine release and cytotoxicity against tumors and dendritic cells. Proc Natl Acad Sci U S A (2004) 101(27):10116-21. doi:10.1073/pnas. 0403744101

26. Marcenaro E, Ferranti B, Falco M, Moretta L, Moretta A. Human NK cells directly recognize Mycobacterium bovis via TLR2 and acquire the ability to kill monocyte-derived DC. Int Immunol (2008) 20(9):1155-67. doi:10.1093/ intimm/dxn073
27. Hayakawa Y, Huntington ND, Nutt SL, Smyth MJ. Functional subsets of mouse natural killer cells. Immunol Rev (2006) 214:47-55. doi:10.1111/j.1600-065X.2006.00454.x

28. Cooper MA, Caligiuri MA. Isolation and characterization of human natural killer cell subsets. Curr Protoc Immunol (2004) Chapter 7:Unit7.34. doi:10.1002/0471142735.im0734s60

29. Ferlazzo G, Thomas D, Lin S-L, Goodman K, Morandi B, Muller WA, et al. The abundant NK cells in human secondary lymphoid tissues require activation to express killer cell Ig-like receptors and become cytolytic. J Immunol (2004) 172(3):1455-62. doi:10.4049/jimmunol.172.3.1455

30. Freud AG, Yokohama A, Becknell B, Lee MT, Mao HC, Ferketich AK, et al. Evidence for discrete stages of human natural killer cell diff erentiation in vivo. J Exp Med (2006) 203(4):1033-43. doi:10.1084/jem.20052507

31. Freud AG, Yu J, Caligiuri MA. Human natural killer cell development in secondary lymphoid tissues. Semin Immunol (2014) 26(2):132-7. doi:10.1016/j. smim.2014.02.008

32. Di Santo JP, Vosshenrich CAJ. Bone marrow versus thymic pathways of natural killer cell development. Immunol Rev (2006) 214:35-46. doi:10.1111/j.1600-065X.2006.00461.x

33. Anfossi N, André P, Guia S, Falk CS, Roetynck S, Stewart CA, et al. Human NK cell education by inhibitory receptors for MHC class I. Immunity (2006) 25(2):331-42. doi:10.1016/j.immuni.2006.06.013

34. Orange JS, Wang B, Terhorst C, Biron CA. Requirement for natural killer cell-produced interferon gamma in defense against murine cytomegalovirus infection and enhancement of this defense pathway by interleukin 12 administration. J Exp Med (1995) 182(4):1045-56. doi:10.1084/jem.182.4.1045

35. Biron CA, Nguyen KB, Pien GC, Cousens LP, Salazar-Mather TP. Natural killer cells in antiviral defense: function and regulation by innate cytokines. Annu Rev Immunol (1999) 17(1):189-220. doi:10.1146/annurev. immunol.17.1.189

36. Warren HS, Kinnear BF, Phillips JH, Lanier LL. Production of IL-5 by human NK cells and regulation of IL-5 secretion by IL-4, IL-10, and IL-12. J Immunol (1995) 154(10):5144-52.

37. Peritt D, Robertson S, Gri G, Showe L, Aste-Amezaga M, Trinchieri G. Differentiation of human NK cells into NK1 and NK2 subsets. J Immunol (1998) 161(11):5821-4.

38. Perona-Wright G, Mohrs K, Szaba FM, Kummer LW, Madan R, Karp CL, et al. Systemic but not local infections elicit immunosuppressive IL-10 production by natural killer cells. Cell Host Microbe (2009) 6(6):503-12. doi:10.1016/j. chom.2009.11.003

39. Passos ST, Silver JS, O’Hara AC, Sehy D, Stumhofer JS, Hunter CA. IL-6 promotes NK cell production of IL-17 during toxoplasmosis. J Immunol (2010) 184(4):1776-83. doi:10.4049/jimmunol.0901843

40. Kumar P, Thakar MS, Ouyang W, Malarkannan S. IL-22 from conventional NK cells is epithelial regenerative and inflammation protective during influenza infection. Mucosal Immunol (2013) 6(1):69-82. doi:10.1038/mi.2012.49

41. Xu X, Weiss ID, Zhang H, Singh SP, Wynn TA, Wilson MS, et al. Conventional NK cells can produce IL-22 and promote host defense in Klebsiella pneumoniae pneumonia. J Immunol (2014) 192(4):1778-86. doi:10.4049/ jimmunol.1300039

42. Cuturi MC, Anegón I, Sherman F, Loudon R, Clark SC, Perussia B, et al. Production of hematopoietic colony-stimulating factors by human natural killer cells. J Exp Med (1989) 169(2):569-83. doi:10.1084/jem.169.2.569

43. Oliva A, Kinter AL, Vaccarezza M, Rubbert A, Catanzaro A, Moir S, et al. Natural killer cells from human immunodeficiency virus (HIV)-infected individuals are an important source of CC-chemokines and suppress HIV-1 entry and replication in vitro. J Clin Invest (1998) 102(1):223-31. doi:10.1172/ JCI2323

44. Roda JM, Parihar R, Magro C, Nuovo GJ, Tridandapani S, Carson WE. Natural killer cells produce $\mathrm{T}$ cell-recruiting chemokines in response to antibody-coated tumor cells. Cancer Res (2006) 66(1):517-26. doi:10.1158/ 0008-5472.CAN-05-2429

45. Bluman EM, Bartynski KJ, Avalos BR, Caligiuri MA. Human natural killer cells produce abundant macrophage inflammatory protein-1 alpha in response to monocyte-derived cytokines. J Clin Invest (1996) 97(12):2722-7. doi:10.1172/JCI118726

46. Smyth MJ, Zachariae CO, Norihisa Y, Ortaldo JR, Hishinuma A, Matsushima K. IL-8 gene expression and production in human peripheral blood lymphocyte subsets. J Immunol (1991) 146(11):3815-23. 
47. Fehniger TA, Shah MH, Turner MJ, VanDeusen JB, Whitman SP, Cooper MA, et al. Differential cytokine and chemokine gene expression by human NK cells following activation with IL-18 or IL-15 in combination with IL-12: implications for the innate immune response. J Immunol (1999) 162(8):4511-20.

48. Fauriat C, Long EO, Ljunggren H-G, Bryceson YT. Regulation of human NK-cell cytokine and chemokine production by target cell recognition. Blood (2010) 115(11):2167-76. doi:10.1182/blood-2009-08-238469

49. Kim M, Kim T-J, Kim HM, Doh J, Lee K-M. Multi-cellular natural killer (NK) cell clusters enhance NK cell activation through localizing IL-2 within the cluster. Sci Rep (2017) 7:40623. doi:10.1038/srep40623

50. Lodoen MB, Lanier LL. Natural killer cells as an initial defense against pathogens. Curr Opinion Immunol (2006) 18:391-8. doi:10.1016/j.coi.2006.05.002

51. Doolan DL, Hoffman SL. IL-12 and NK cells are required for antigen-specific adaptive immunity against malaria initiated by $\mathrm{CD}^{+} \mathrm{T}$ cells in the Plasmodium yoelii model. J Immunol (1999) 163(2):884-92.

52. Garcia-Penarrubia P, Koster FT, Kelley RO, Mcdowell ITD, Bankhurst AD. Antibacterial activity of human natural killer cells. JExp Med (1989) 169(1):99-113. doi:10.1084/jem.169.1.99

53. Brown MG, Dokun AO, Heusel JW, Smith HR, Beckman DL, Blattenberger EA, et al. Vital involvement of a natural killer cell activation receptor in resistance to viral infection. Science (2001) 292(5518):934-7. doi:10.1126/science.1060042

54. Daniels KA, Devora G, Lai WC, O’Donnell CL, Bennett M, Welsh RM. Murine cytomegalovirus is regulated by a discrete subset of natural killer cells reactive with monoclonal antibody to Ly49H. J Exp Med (2001) 194(1):29-44. doi:10.1084/jem.194.1.29

55. Flynn JL, Chan J, Triebold KJ, Dalton DK, Stewart TA, Bloom BR. An essential role for interferon gamma in resistance to Mycobacterium tuberculosis infection. J Exp Med (1993) 178:2249-54. doi:10.1084/jem.178.6.2249

56. Treerat P, Prince O, Cruz-Lagunas A, Muñoz-Torrico M, Salazar-Lezama MA, Selman M, et al. Novel role for IL-22 in protection during chronic Mycobacterium tuberculosis HN878 infection. Mucosal Immunol (2017) 10(4): 1069-81. doi:10.1038/mi.2017.15

57. Vankayalapati R, Barnes PF. Innate and adaptive immune responses to human Mycobacterium tuberculosis infection. Tuberculosis (2009) 89:S77-80. doi:10.1016/S1472-9792(09)70018-6

58. Méndez A, Granda H, Meenagh A, Contreras S, Zavaleta R, Mendoza MF, et al. Study of KIR genes in tuberculosis patients. Tissue Antigens (2006) 68(5):386-9. doi:10.1111/j.1399-0039.2006.00685.x

59. Mahfouz R, Halas H, Hoteit R, Saadeh M, Shamseddeen W, Charafeddine K, et al. Study of KIR genes in Lebanese patients with tuberculosis. Int J Tuberc Lung Dis (2011) 15(12):1688-90. doi:10.5588/ijtld.11.0138

60. Pydi SS, Sunder SR, Venkatasubramanian S, Kovvali S, Jonnalagada S, Valluri VL. Killer cell immunoglobulin like receptor gene association with tuberculosis. Hum Immunol (2013) 74(1):85-92. doi:10.1016/j.humimm.2012.10.006

61. Salie M, Daya M, Miller M, Hoal EG. Activating KIRs alter susceptibility to pulmonary tuberculosis in a South African population. Tuberculosis (2015) 95(6):817-21. doi:10.1016/j.tube.2015.09.003

62. Portevin D, Via LE, Eum S, Young D. Natural killer cells are recruited during pulmonary tuberculosis and their ex vivo responses to mycobacteria vary between healthy human donors in association with KIR haplotype. Cell Microbiol (2012) 14(11):1734-44. doi:10.1111/j.1462-5822.2012.01834.x

63. Batoni G, Esin S, Favilli F, Pardini M, Bottai D, Maisetta G, et al. Human CD56 $6^{\text {bight }}$ and $\mathrm{CD} 56^{\text {dim }}$ natural killer cell subsets respond differentially to direct stimulation with Mycobacterium bovis bacillus Calmette-Guerin. Scand J Immunol (2005) 62(6):498-506. doi:10.1111/j.1365-3083.2005.01692.x

64. Bozzano F, Costa P, Passalacqua G, Dodi F, Ravera S, Pagano G, et al. Functionally relevant decreases in activatory receptor expression on NK cells are associated with pulmonary tuberculosis in vivo and persist after successful treatment. Int Immunol (2009) 21(7):779-91. doi:10.1093/ intimm/dxp046

65. Barcelos W, Sathler-Avelar R, Martins-Filho OA, Carvalho BN, Guimarães TMPD, Miranda SS, et al. Natural killer cell subpopulations in putative resistant individuals and patients with active Mycobacterium tuberculosis infection. Scand J Immunol (2008) 68(1):92-102. doi:10.1111/j. 1365-3083.2008.02116.x

66. Fan R, Xiang Y, Yang L, Liu Y, Chen P, Wang L, et al. Impaired NK cells' activity and increased numbers of $\mathrm{CD}^{+} \mathrm{CD}^{2} 5^{+}$regulatory $\mathrm{T}$ cells in multidrug- resistant Mycobacterium tuberculosis patients. Tuberculosis (2016) 98:13-20. doi:10.1016/j.tube.2016.02.001

67. Feng CG, Kaviratne M, Rothfuchs AG, Cheever A, Hieny S, Young HA, et al. NK cell-derived IFN-gamma differentially regulates innate resistance and neutrophil response in $\mathrm{T}$ cell-deficient hosts infected with Mycobacterium tuberculosis. J Immunol (2006) 177(10):7086-93. doi:10.4049/ jimmunol.177.10.7086

68. Junqueira-Kipnis AP, Kipnis A, Jamieson A, Juarrero MG, Diefenbach A, Raulet DH, et al. NK cells respond to pulmonary infection with Mycobacterium tuberculosis, but play a minimal role in protection. JImmunol (2003) 171(11):6039-45. doi:10.4049/jimmunol.171.11.6039

69. Vély F, Barlogis V, Vallentin B, Neven B, Piperoglou C, Ebbo M, et al. Evidence of innate lymphoid cell redundancy in humans. Nat Immunol (2016) 17(11):1291-9. doi:10.1038/ni.3553

70. Bando JK, Colonna M. Innate lymphoid cell function in the context of adaptive immunity. Nat Immunol (2016) 17(7):783-9. doi:10.1038/ni.3484

71. World Health Organization. WHO Global Tuberculosis Report. Geneva: World Health Organization (2017). Available from: http://www.who.int/ mediacentre/factsheets/fs104/en/

72. Vankayalapati R, Klucar P, Wizel B, Weis SE, Samten B, Safi H, et al. NK cells regulate $\mathrm{CD}^{+} \mathrm{T}$ cell effector function in response to an intracellular pathogen. J Immunol (2003) 172(1):130-7. doi:10.4049/jimmunol. 172.1.130

73. Roy S, Barnes P, Garg A, Wu S, Cosman D, Vankayalapati R. NK cells lyse $\mathrm{T}$ regulatory cells that expand in response to an intracellular pathogen. J Immunol (2008) 180:1729-36. doi:10.4049/jimmunol.180.3.1729

74. Esin S, Batoni G, Counoupas C, Stringaro A, Brancatisano FL, Colone M, et al. Direct binding of human NK cell natural cytotoxicity receptor NKp44 to the surfaces of mycobacteria and other bacteria. Infect Immun (2008) 76(4):1719-27. doi:10.1128/IAI.00870-07

75. Esin S, Counoupas C, Aulicino A, Brancatisano FL, Maisetta G, Bottai D, et al. Interaction of Mycobacterium tuberculosis cell wall components with the human natural killer cell receptors NKp44 and toll-like receptor 2. Scand J Immunol (2013) 77(6):460-9. doi:10.1111/sji.12052

76. Vankayalapati R, Wizel B, Weis SE, Safi H, Lakey DL, Mandelboim O, et al. The NKp46 receptor contributes to NK cell the NKp46 receptor contributes to NK cell lysis of mononuclear phagocytes infected with an intracellular bacterium 1. J Immunol (2002) 168:3451-7. doi:10.4049/jimmunol.168.7.3451

77. Vankayalapati R, Garg A, Porgador A, Griffith DE, Klucar P, Safi H, et al. Role of NK cell-activating receptors and their ligands in the lysis of mononuclear phagocytes infected with an intracellular bacterium. JImmunol (2005) 175(7):4611-7. doi:10.4049/jimmunol.175.7.4611

78. Garg A, Barnes PF, Porgador A, Roy S, Wu S, Nanda JS, et al. Vimentin expressed on Mycobacterium tuberculosis-infected human monocytes is involved in binding to the NKp46 receptor. J Immunol (2006) 177(9):6192-8. doi:10.4049/jimmunol.177.9.6192

79. Dhiman R, Indramohan M, Barnes PF, Nayak RC, Paidipally P, Rao LVM, et al. IL-22 produced by human NK cells inhibits growth of Mycobacterium tuberculosis by enhancing phagolysosomal fusion. J Immunol (2009) 183(10):6639-45. doi:10.4049/jimmunol.0902587

80. Dhiman R, Venkatasubramanian S, Paidipally P, Barnes PF, Tvinnereim A, Vankayalapati R. Interleukin 22 inhibits intracellular growth of Mycobacterium tuberculosis by enhancing calgranulin A expression. J Infect Dis (2014) 209(4):578-87. doi:10.1093/infdis/jit495

81. Lu C-C, Wu T-S, Hsu Y-J, Chang C-J, Lin C-S, Chia J-H, et al. NK cells kill mycobacteria directly by releasing perforin and granulysin. J Leukoc Biol (2014) 96:1-11. doi:10.1189/jlb.4A0713-363RR

82. Schierloh P, Yokobori N, Aleman M, Landoni V, Geffner L, Musella RM, et al. Mycobacterium tuberculosis-induced gamma interferon production by natural killer cells requires cross talk with antigen-presenting cells involving Toll-like receptors 2 and 4 and the mannose receptor in tuberculous pleurisy. Infect Immun (2007) 75(11):5325-37. doi:10.1128/IAI.00381-07

83. Dhiman R, Periasamy S, Barnes PF, Jaiswal AG, Paidipally P, Barnes AB, et al. $\mathrm{NK} 1.1^{+}$cells and IL-22 regulate vaccine-induced protective immunity against challenge with Mycobacterium tuberculosis. J Immunol (2012) 189(2):897-905. doi:10.4049/jimmunol.1102833

84. Peng H, Jiang X, Chen Y, Sojka DK, Wei H, Gao X, et al. Liver-resident NK cells confer adaptive immunity in skin-contact inflammation. J Clin Invest (2013) 123(4):1444-56. doi:10.1172/JCI66381 
85. van den Boorn JG, Jakobs C, Hagen C, Renn M, Luiten RM, Melief CJM, et al. Inflammasome-dependent induction of adaptive NK cell memory. Immunity (2016) 44(6):1406-21. doi:10.1016/j.immuni.2016.05.008

86. Sun JC, Madera S, Bezman NA, Beilke JN, Kaplan MH, Lanier LL. Proinflammatory cytokine signaling required for the generation of natural killer cell memory. J Exp Med (2012) 209(5):947-54. doi:10.1084/ jem.20111760

87. O'Sullivan TE, Johnson L, Kang H, Sun JC. BNIP3- and BNIP3L-mediated mitophagy promotes the generation of natural killer cell memory. Immunity (2015) 43:331-42. doi:10.1016/j.immuni.2015.07.012

88. Richer MJ, Pewe LL, Hancox LS, Hartwig SM, Varga SM, Harty JT. Inflammatory IL-15 is required for optimal memory $\mathrm{T}$ cell responses. J Clin Invest (2015) 125(9):3477-90. doi:10.1172/JCI81261

89. Firth MA, Madera S, Beaulieu AM, Gasteiger G, Castillo EF, Schluns KS, et al. Nfil3-independent lineage maintenance and antiviral response of natural killer cells. J Exp Med (2013) 210(13):2981-90. doi:10.1084/jem. 20130417

90. Zawislak CL, Beaulieu AM, Loeb GB, Karo J, Canner D, Bezman NA, et al. Stage-specific regulation of natural killer cell homeostasis and response against viral infection by microRNA-155. Proc Natl Acad Sci U S A (2013) 110(17):6967-72. doi:10.1073/pnas.1304410110

91. Gumá M, Cabrera C, Erkizia I, Bofill M, Clotet B, Ruiz L, et al. Human cytomegalovirus infection is associated with increased proportions of NK cells that express the CD94/NKG2C receptor in aviremic HIV-1-positive patients. J Infect Dis (2006) 194:38-41. doi:10.1086/504719

92. Gumá M, Cabrera C, Erkizia I, Bofill M, Clotet B, Ruiz L, et al. Expansion of CD94/NKG2C ${ }^{+} \mathrm{NK}$ cells in response to human cytomegalovirusinfected fibroblast. Blood (2006) 107:3624-31. doi:10.1182/blood-200509-3682

93. López-Verges S, Milush J, Schwartz B, Pando M, Jarjoura J, York V, et al. Expansion of a unique CD57 ${ }^{+} \mathrm{NKG} 2 \mathrm{Chi}$ natural killer cell subset during acute human cytomegalovirus infection. Proc Natl Acad Sci U S A (2011) 108:14725-32. doi:10.1073/pnas.1110900108

94. Foley B, Cooley S, Verneris M, Pitt M, Curtsinger J, Luo X, et al. Cytomegalovirus reactivation after allogeneic transplantation promotes a lasting increase in educated $\mathrm{NKG}_{2} \mathrm{C}^{+}$natural killer cells with potent function. Blood (2012) 119:2665-74. doi:10.1182/blood-2011-10-386995

95. Foley B, Cooley S, Verneris M, Curtsinger J, Luo X, Waller E, et al. Human cytomegalovirus (CMV)-induced memory-like $\mathrm{NKG}_{2} \mathrm{C}^{+} \mathrm{NK}$ cells are transplantable and expand in vivo in response to recipient $\mathrm{CMV}$ antigen. J Immunol (2012) 189:5082-8. doi:10.4049/jimmunol.1201964

96. Bjorkstrom NK, Lindgren T, Stoltz M, Fauriat C, Braun M, Evander M, et al. Rapid expansion and long-term persistence of elevated NK cell numbers in humans infected with hantavirus. JExp Med (2011) 208(1):13-21. doi:10.1084/jem.20100762

97. Petitdemange C, Becquart P, Wauquier N, Béziat V, Debré P, Leroy EM, et al. Unconventional repertoire profile is imprinted during acute chikungunya infection for natural killer cells polarization toward cytotoxicity. PLoS Pathog (2011) 7(9):e1002268. doi:10.1371/journal.ppat.1002268

98. Béziat V, Dalgard O, Asselah T, Halfon P, Bedossa P, Boudifa A, et al. CMV drives clonal expansion of $\mathrm{NKG}_{2} \mathrm{C}^{+} \mathrm{NK}$ cells expressing self-specific KIRs in chronic hepatitis patients. Eur J Immunol (2012) 42:447-57. doi:10.1002/ eji.201141826

99. Tiemessen CT, Shalekoff S, Meddows-Taylor S, Schramm DB, Papathanasopoulos M, Gray G, et al. Natural killer cells that respond to human immunodeficiency virus type 1 (HIV-1) peptides are associated with control of HIV-1 infection. J Infect Dis (2010) 202(9):1444-53. doi:10.1086/ 656535

100. Brunetta E, Fogli M, Varchetta S, Bozzo L, Hudspeth K, Marcenaro E, et al. Chronic HIV-1 viremia reverses NKG2A/NKG2C ration on natural killer cells in patients with human cytomegalovirus coninfection. AIDS (2010) 24:27-34. doi:10.1097/QAD.0b013e3283328d1f

101. Dou Y, Fu B, Sun R, Li W, Hu W, Tian Z, et al. Influenza vaccine induces intracellular immune memory of human NK cells. PLoS One (2015) 10(3):e0121258. doi:10.1371/journal.pone.0121258

102. Stevenson HL, Estes MD, Thirumalapura NR, Walker D, Ismail N. Natural killer cells promote tissue injury and systemic inflammatory responses during fatal Ehrlichia-induced toxic shock-like syndrome. Am J Pathol (2010) 177(2):766-76. doi:10.2353/ajpath.2010.091110
103. Cooper MA, Elliott J, Keyel P, Yang L, Carrero J, Yokoyama WM. Cytokineinduced memory-like natural killer cells. Proc Natl Acad Sci U S A (2009) 106(6):1915-9. doi:10.1073/pnas.0813192106

104. Romee R, Schneider SE, Leong JW, Chase JM, Keppel CR, Sullivan RP, et al. Cytokine activation induces human memory-like NK cells. Blood (2012) 120(24):4751-60. doi:10.1182/blood-2012-04-419283

105. Leong JW, Chase JM, Romee R, Schneider SE, Sullivan RP, Cooper MA, et al. Preactivation with IL-12, IL-15, and IL-18 induces CD25 and a functional high-affinity IL-2 receptor on human cytokine-induced memory-like natural killer cells. Biol Blood Marrow Transplant (2014) 20(4):463-73. doi:10.1016/j. bbmt.2014.01.006

106. Fu X, Liu Y, Li L, Li Q, Qiao D, Wang H, et al. Human natural killer cells expressing the memory-associated marker CD45RO from tuberculous pleurisy respond more strongly and rapidly than CD45RO- natural killer cells following stimulation with interleukin-12. Immunology (2011) 134(1):41-9. doi:10.1111/j.1365-2567.2011.03464.x

107. Fu X, Yu S, Yang B, Lao S, Li B, Wu C. Memory-like antigen-specific human NK cells from TB pleural fluids produced IL-22 in response to IL-15 or Mycobacterium tuberculosis antigens. PLoS One (2016) 11(3):e151721. doi:10.1371/journal.pone.0151721

108. Suliman S, Geldenhuys H, Johnson JL, Hughes JE, Smit E, Murphy M, et al. Bacillus Calmette-Guérin (BCG) revaccination of adults with latent Mycobacterium tuberculosis infection induces long-lived BCG-reactive NK cell responses. JImmunol (2016) 197(4):1100-10. doi:10.4049/ jimmunol.1501996

109. Kleinnijenhuis J, Quintin J, Preijers F, Joosten L, Jacobs C, Xavier R, et al. BCG-induced trained immunity in NK cells: role for non-specific protection to infection. Clin Immunol (2014) 155(2):213-9. doi:10.1016/j. clim.2014.10.005

110. Kawahara M, Hasegawa N, Takaku H. Murine splenic natural killer cells do not develop immunological memory after re-encounter with Mycobacterium bovis BCG. PLoS One (2016) 11(3):1-13. doi:10.1371/journal.pone.0152051

111. Jiang X, Chen Y, Peng H, Tian Z. Memory NK cells: why do they reside in the liver? Cell Mol Immunol (2013) 10(3):196-201. doi:10.1038/cmi.2013.8

112. Venkatasubramanian S, Cheekatla S, Paidipally P, Tripathi D, Welch E, Tvinnereim AR, et al. IL-21-dependent expansion of memory-like NK cells enhances protective immune responses against Mycobacterium tuberculosis. Mucosal Immunol (2017) 10(4):1031-42. doi:10.1038/mi.2016.105

113. Chu T, Tyznik A, Roepke S, Berkley A, Woodward-Davis A, Pattacini L, et al. Bystander-activated memory CD8 T cells control early pathogen load in an innate-like, NKG2D-dependent manner. Cell Rep (2013) 3(3):701-8. doi:10.1016/j.celrep.2013.02.020

114. Sun JC, Ugolini S, Vivier E. Immunological memory within the innate immune system. EMBO J (2014) 33(12):1295-303. doi:10.1002/embj.201387651

115. Netea MG, Latz E, Kingston HG, Mills LA, Neill JO. Innate immune memory: a paradigm shift in understanding host defense. Nat Immunol (2015) 16(7):675-9. doi:10.1038/ni.3178

116. Vivier E, van de Pavert SA, Cooper MD, Belz GT. The evolution of innate lymphoid cells. Nat Immunol (2016) 17(7):790-4. doi:10.1038/ni.3459

117. Cambier CJ, Takaki KK, Larson RP, Hernandez RE, Tobin DM, Urdahl KB, et al. Mycobacteria manipulate macrophage recruitment through coordinated use of membrane lipids. Nature (2014) 505(7482):218-22. doi:10.1038/ nature 12799

118. Lang PA, Lang KS, Xu HC, Grusdat M, Parish IA, Recher M, et al. Natural killer cell activation enhances immune pathology and promotes chronic infection by limiting CD8 ${ }^{+}$T-cell immunity. Proc Natl Acad Sci U S A (2012) 109(4):1210-5. doi:10.1073/pnas.1118834109

119. Zhou G, Juang SWW, Kane KP. NK cells exacerbate the pathology of influenza virus infection in mice. Eur J Immunol (2013) 43(4):929-38. doi:10.1002/ eji.201242620

120. Abdul-Careem MF, Mian MF, Yue G, Gillgrass A, Chenoweth MJ, Barra NG, et al. Critical role of natural killer cells in lung immunopathology during influenza infection in mice. J Infect Dis (2012) 206(2):167-77. doi:10.1093/ infdis/jis 340

121. Wolf A-S, Sherratt S, Riley EM. NK cells: uncertain allies against malaria. Front Immunol (2017) 8:212. doi:10.3389/fimmu.2017.00212

122. Morandi B, Bramanti P, Bonaccorsi I, Montalto E, Oliveri D, Pezzino G, et al. Role of natural killer cells in the pathogenesis and progression of multiple sclerosis. Pharmacol Res (2008) 57(1):1-5. doi:10.1016/j.phrs.2007.11.003 
123. Gross CC, Schulte-Mecklenbeck A, Wiendl H, Marcenaro E, Kerlero de Rosbo N, Uccelli A, et al. Regulatory functions of natural killer cells in multiple sclerosis. Front Immunol (2016) 7:606. doi:10.3389/fimmu.2016.00606

Conflict of Interest Statement: The authors declare that the research was conducted in the absence of any commercial or financial relationships that could be construed as a potential conflict of interest.
Copyright (® 2017 Choreño Parra, Martínez Zúñiga, Jiménez Zamudio, Jiménez Álvarez, Salinas Lara and Zúniga. This is an open-access article distributed under the terms of the Creative Commons Attribution License (CC BY). The use, distribution or reproduction in other forums is permitted, provided the original author(s) or licensor are credited and that the original publication in this journal is cited, in accordance with accepted academic practice. No use, distribution or reproduction is permitted which does not comply with these terms. 